\title{
ESTUDOS SOBRE O IMAGINÁRIO NA ATMOSFERA DE QUILOMBOS ARQUEOLÓGICOS
}

Studies on the imaginary in the atmosphere of Quilombo archaeological

Cláudio Baptista Carle ${ }^{1}$

\section{RESUMO}

Estudo sobre os diversos imaginários nas pesquisas de quilombos arqueológicos brasileiros, realizadas no Rio Grande do Sul, nos últimos anos, considerando seus aspectos colaborativos entre ciências e cientistas.

Palavras-chave: Arqueologia, quilombos, imaginário

\section{ABSTRACT}

Study of the various figures in the Brazilian archaeological research Quilombo, held in Rio Grande do Sul, in recent years, considering its collaborative aspects of science and scientists.

Keywords: Archaeology, quilombos, imaginary

\section{RESUMEN}

Investigación sobre los diversos imaginarios en los estudios arqueológicos en "quilombos" (sitios cimarrones) brasileños, celebradas en Rio Grande do Sul, en los últimos años, teniendo en cuenta sus aspectos de colaboración de la ciencia y de los científicos.

Palabras clave: arqueología, Quilombo, imaginario

\section{Introdução}

Gitibá Faustino (1991: 102) diz que o Brasil é o segundo país do mundo em população negra, sendo que o primeiro seria a Nigéria; me pergunto onde isso influi na arqueologia? A resposta está na imagem (DURAND, 1997) arqueológica sobre vestígios de afro-americanos. A atmosfera, o imaginário acadêmico, é de colaboração entre pesquisadores envolvidos na investigação do tema. "O imaginário é determinado pela ideia de fazer parte de algo" (SILVA, 2012). É sobre imaginário, esta atmosfera ou aura que o texto discorre.

\footnotetext{
${ }^{1}$ LAMINA e PPGA (ICH) - GEPIEM (FAE) - UFPel , Doutor em História- Area de Concentração em Arqueologia (PUCRS). cbcarle@yahoo.com.br
} 
Segui ideias convergentes que implicam em uma ação colaborativa. Aura instauradora (DURAND, 1997: 19) da arqueologia sobre afro-americanos é inteira, torna-se um imperialismo de imagens na ambiência social, "fantasias adversas", "recalcamento" de regimes de imagens fixadas em um "momento histórico" (DURAND, 1997: 390). O imaginário revela as ações e as formas de entender o ser no mundo. A aura, imaginário, é instauradora das formas de pensar, sentir e agir. Gilbert Durand, no universo simbólico dos textos, neste caso sobre afro-americanos no sul do Brasil, indica que há uma troca incessante entre as pulsões subjetivas (biopsíquicas) e as intimações objetivas (cósmico-sócio-culturais) que se processa no trajeto antropológico. Que há um dinamismo equilibrador entre pensadores, as grandes imagens tradicionais e as míticas. Mitos que penetram nas orientações mais profundas (DURAND, 1997: 13) da sociedade científica. Há uma instauração do pensar sobre os afro-americanos.

Esperava encontrar uma construção colaborativa, imaginada e apresentada nos textos de forma utópica, mas verifiquei ideias individuais de cunho político sobre os vestígios de afro-americanos. É uma visão recalcada.

Nenhum lugar é deixado à «Imaginação criadora», ao Imaginário poético. É talvez daí que data a catástrofe que separou o Oriente e o Ocidente em nível do pensamento, o pensamento visionário e o pensamento racional, desde Guillaume d'Auvergne até Descartes, passando por São Tomás de Aquino. O imaginário tornase aqui no Ocidente cada vez mais recalcado na insignificação ornamental, estética, e, na véspera do século romântico, o divórcio está consumido. (DURAND, 2004: 10)

A visão de recalcamento ocidental (sistema imaginal instalado), expresso nas ciências humanas, é fixada pela imagem científica redutora (cartesiana) que se desenvolve no Brasil. Estamos então frente a um recalcamento da ciência ocidental, também na arqueologia brasileira. Investigo este recalcamento nos estudos sobre quilombos e vestígios de afroamericanos.

“O imaginário é a marca digital simbólica do indivíduo ou do grupo na matéria do vivido. Como reservatório, o imaginário é essa impressão digital do ser no mundo" (SILVA, 2012). Sofri, como arqueólogo, este processo de impregnação simbólica. Esta marca simbólica aparece desde o início do século; percebo-a a partir das discussões travadas com Klaus Hilbert, Arno Kern e Moacyr Flores. Surge então este texto, no limiar entre o cartesianismo e os estudos sobre o imaginário. As "práticas de fronteira são marcadas não somente por relações de 'boa vizinhança', mas também pelo litígio" (GOMES, 2000: 7). O 
litígio em foco é a possibilidade de compreender a aura que se estabeleceu nos estudos sobre os afro-americanos no RS.

$\mathrm{Na}$ arqueologia brasileira, vemos que a reprodução de velhos modelos, sem uma discussão teórica maior, ainda é persistente. "Uma ciência atinge sua maturidade quando ela conhece seus limites" (KERN, 2002: 116). Não há estes limites e os trabalhos são individualistas, feitos por um cientista que quer se entender múltiplo e que pretende dominar tudo. Um imaginário de regime diurno e com esquema postural heróico (DURAND, 1997: 115-121), um super-homem das ciências.

Sigfried Laet coloca o problema da arqueologia na origem, na vinculação com outras disciplinas, perdendo o seu veio condutor, expressando desejos de estudos, na maioria das vezes, individuais, da História da Arte, das Ciências Naturais e da História propriamente dita, perdendo sua constituição própria (LAET, 1959: 14-24).

Para Schmitz (1982: 53) a Arqueologia no Brasil procura reconstruir o modo de vida - a tecnologia, a cultura, a sociedade - de populações passadas ou etapas das atuais populações para as quais outras documentações são nulas ou ineficientes, não possuindo problemas, nem teorias exclusivas, partilhando estas com outras ciências. É uma síntese, uma especialização destacada de outras ciências, mas a arqueologia brasileira, na sua aura (imaginário), se pensa total. “O imaginário, para mim, é essa aura, é da ordem da aura: uma atmosfera. O espírito positivista não pode aceitar como vetor de ação algo tão impalpável, apresentado como atmosfera, admitido como aura" (SILVA, 2012).

O imaginário é uma sensação que é vivida e não uma ordem de coisas mensuráveis que podem ser quantificadas. Imbuído também por esta sensação, busco entender a atmosfera do estudo arqueológico sobre áreas com vestígios de afro-americanos.

\section{Atmosfera para compreender os quilombos arqueológicos}

Há um reservatório, um motor que agrega imagens, sentimentos, lembranças, experiências, visões do real que realizam o imaginado, leituras da vida individual e grupal que sedimentam um modo de ver em objetos, como espaços, objetos móveis, estruturas. Ali estão registradas as formas de ser, de agir, de sentir e de pensar o futuro ao se estar no mundo. $\mathrm{O}$ imaginário "emana do real, estrutura-se como ideal e retorna ao real como elemento propulsor" e como forma nas ações humanas que constituem os sítios que ocupa (SILVA, 2012; DURAND, 2004). 
Estudar sítios arqueológicos históricos tem sido estudar a história dos seus formadores (LIMA, 1985: 88). Esta é a atmosfera da arqueologia histórica no Brasil. "O cientista não pode eliminar inteiramente o seu imaginário para atuar em condições absolutas de objetividade e de neutralidade. A ciência também tem a sua aura. O cientista também se move numa atmosfera" (SILVA, 2012). A atmosfera da "história do negro" e da "arqueologia da escravidão" (como se pensa o estudo sobre afro-americanos) marca os estudos. Assim, entender a atmosfera da história é entender o imaginário que envolve os estudos arqueológicos até o presente.

O estudo sobre os afro-americanos é marcado pelo "branqueamento", constituindo uma atmosfera de segregação racial historiográfica no país (SANTOS, 1991: 81-82), refletindo nos sentidos comuns (MAFFESOLI, 1994) da população diretamente envolvida e em seus movimentos organizados. Efeito que marca as posições, os ideologemas, que são a materialização de valores e de funções ideológicas de um determinado meio social, sendo psíquico e social; por consequência, ideológico, constituindo a materialidade da "ideologia" no cotidiano da vida social (DURAND, 1997: 118).

$\mathrm{Na}$ historiografia refletida na arqueologia (LIMA, 1985) aparecem estes ideologemas. Escravos realizavam os assassinatos dos proprietários (MOREIRA, 1995), Luis Gama - filho de escravo rebelde - afirmava "que o escravo que matava o seu senhor praticava um ato de legítima defesa" (MOURA, 1987: 80). A confusão ideológica, ideologemas racistas e a atmosfera científica se conflitam. O Movimento Negro, na região meridional do RS, ao entender que o cientista trata os escravos como agressivos, inquiriu historiadores que escreveram sobre isso, a exemplo da obra de Roger da Silva intitulada Muzungas: Consumo e manuseio de químicas por escravos e libertos no Rio Grande do Sul (1828-1888) (Pelotas: EDUCAT, 2001) que foi levada à investigação como uma obra racista, por dizer que os afroamericanos envenenavam seus senhores no período da escravidão. Neste caso, o historiadorautor é afro-americano e seu texto traz os registros históricos e não promove racismo de forma alguma. Insurreições e revoltas também aparecem como formas de oposição à escravidão (SANTOS, 1991: 79; MAESTRI, 1979: 53 e 94; GOMES et al, 1995: 28). Percebe-se contradição na escrita histórica, aura dos estudos arqueológicos (FUNARI, 1996), em relação à percepção dos envolvidos.

Mariano Santos - ex-escravo, afirmava que os escravos se suicidavam, apenas esperando a morte de sede, de fome ou de enfermidade, "o dia que Deus chamava" (MAESTRI, 1988: 31). A morte, na atmosfera historiográfica, é colocada como perda mercantil, de força produtiva, que podia assumir proporções endêmicas (MAESTRI, 1979: 
47). A aura econômica amplia a atmosfera das pesquisas. Na urbanização, fugitivos passavam por livres "de cor", procuravam a proteção de um liberto ou de um senhor de escravos, “acoutando-se", fato punível por lei (MAESTRI, 1979). Sant-Hilaire (apud MAESTRI, 1979: 80-89) notava que os mais valentes soldados de Artigas eram escravos fugitivos. Presos, os fujões "continuavam causando prejuízos, pois pagos os captores" (desde 1574) as fugas continuavam, aumentando as despesas com os que permaneciam e com os que eram caçados (MAESTRI, 1984: 73-74).

A fuga é uma constante. "A maneira mais simples, segura e rápida de um cativo libertar-se era a fuga" (MAESTRI, 1984: 73). Aferida simplicidade é reveladora de uma naturalidade na fuga que não expressa o fato. No Jornal $\mathrm{O}$ Mensageiro, Farroupilha que pregava a república e a futura libertação de escravos, nas suas 37 tiragens, em 11 anúncios condena a fuga de escravos. As fugas podiam posteriormente levar à formação de "mocambos" e "quilombos" (SANTOS, 1991: 75; GOMES et al, 1995: 33). As Irmandades, fenômenos urbanos ligados aos "terreiros" e "batuques", frequentados por escravos, libertos e livres pobres (MAESTRI, 1984: 54), eram importantes no apoio às fugas (GOMES et al, 1995: 29). A imagem criada por estes estudos é econômica, uma atmosfera econômica para a escravidão e para a fuga.

As fugas são evidenciadas na historiografia no estudo sobre quilombos. No RS, surgem diversos pequenos quilombos. Quilombos estes que vão além da definição inicial: "toda a habitação de negros fugidos que passem de cinco, em parte despovoada, ainda que não tenham ranchos levantados nem se achem pilões neles" (Rei de Portugal ao Conselho Ultramarino, datada de 2 de dezembro de 1740, apud MOURA, 1987: 16). Formam grupos armados, com lideranças na fuga e que se perpetuavam. Segmentos pobres ou perseguidos convergiam aos quilombos.

O texto arqueológico, dos lugares (sítios e paisagem) e dos objetos, cria um sentido, uma atmosfera, para compreender os quilombolas. Atmosfera não respeita as ideias criadas pelos próprios grupos a partir de suas realidades para gerar os lugares. A arqueologia segue este caminho, guiado por seu "trajeto" (DURAND, 1997) enquanto ciência.

A arqueologia de afro-americanos no Brasil está intimamente ligada à História e à história da ciência, gerando sua atmosfera. Marcando este "trajeto", Gustaf Oscar Montelius (1843-1921) cria formas de classificação, para coleções estudadas (TRIGGER, 1992: 150), elege variações de forma e decoração, que foram usadas na seriação dos difusionistas no Brasil. Cultura (da Agricultura, um único tipo de cultivo), como organizações humanas (1780), conceito que indica que uma sociedade obedece a padrões definidos, identificáveis, 
como no plantio, visíveis nos artefatos e nos níveis de estratificação diferente de um sítio. Olof Rygh (1866) interpreta pontas de flechas e lanças como "cultura y de un pueblo" da Idade da Pedra (1871), "dos culturas de la Edad de la Piedra y dos pueblos de la Edad de la Piedra" (MEINANDER apud TRIGGER, 1992: 157).

A cultura aplicada nas ciências sociais e aos artefatos arqueológicos cria separações culturais por métodos classificatórios e comparativos, nas aproximações e nas diferenças de produção de bens. Gustaf Kossinna (1858-1931), estudando as "tribus" formadoras da "raça germânica" de origem "indo-européia", em detrimento de outras, divide os vestígios arqueológicos por raças e identifica os povos criativos em contraposição aos povos passivos (TRIGGER, 1992: 159-160). Kossinna busca comprovar a superioridade racial alemã que na dispersão sofria diminuição de suas capacidades criativas. Os amadores, na arqueologia brasileira (cf. André PROUS, 1991), com certeza entraram em contato com os vestígios de afro-americanos, mas não os reconhecem. No Brasil, quilombos foram classificados como áreas de cultura européia ou como áreas de povos não evoluídos, primitivos. $\mathrm{O}$ "Branqueamento" criado por arqueólogos amadores se perpetua. A história e a arqueologia, racistas, mascararam a cultura dos afro-americanos maculando-a (SANTOS, 1991: 141). A atmosfera criada por Jonh Myres (1911) e Arthur Evans (1869), onde a cultura material dos conquistados (passivos) era adotada pelos conquistadores (ativos), se perpetua (TRIGGER, 1992: 162). “A sociedade escravista almejava um cativo que se autoconcebesse como propriedade de outrem ou um negro neutralizado pelo respeito e medo ao amo" (MAESTRI, 1984: 70). A atmosfera onde o afro é inferior, já na arqueologia histórica, o percebe como escravo, ou seja, na sua condição sócio-econômica imposta e não como ente humano. A "arqueologia da escravidão" é um exemplo dessa atmosfera.

A atmosfera modelada pelos textos do PRONAPA toma o lugar dos amadores, fundamentada na ideia de que as culturas tinham um pólo inicial de origem e deste é que se desenvolviam para o resto do mundo (TRIGGER, 1992: 145). A única área de origem possível era colocada no Velho Mundo; dispersos desta por migração ou por difusão, criam blocos ou áreas culturais similares e adjacentes. Franz Boas (1858-1942), baseado em Fredrich Ratzel (1844-1901), incorpora a difusão à capacidade de invenção local. Invenções simples, com única origem, gerando a difusão e as alterações regionais, conforme sua dispersão a partir do centro de origem. A aura de que os africanos vieram pela mão dos europeus sem cultura própria e alterada pela ação daquela cultura superior (TRIGGER, 1992: 159). 
Nos Estados Unidos, os estudos etnográficos das cronologias das culturas, de Kidder (1885-1963), dos métodos taxionômicos de classificação (tipificações são feitas e ramificações encontradas), alicerçadas por esquemas dendríticos de interpretação, com as sequências etnográficas, as tipologias e as seriações, formulam, ao final, tradições arqueológicas e culturas (TRIGGER, 1992: 178-183). No Brasil, a Arqueologia HistóricoCultural, do Smithsonian Instituition (Betty Meggers e Cliford Evans), e a arqueologia amadora brasileira sofrem a influência de um modelo que mescla ideias de Childe (1961) e Montelius (TRIGGER, 1992: 177). Há uma atmosfera de cientificidade na arqueologia.

Meggers e Evans propõem "horizontalidades" e "verticalidades" de maneira difusionista de expansão cultural (1958). A metodologia vertical de um sítio, estratigráfica, classificatória e a seriação do material, intercaladas com as relações comerciais e a datação absoluta realizavam entre sítios o sentido de fases dentro de tradições, fruto de pequenas escavações nos sítios. Este modelo determina-se pelos objetos, perdendo a complexidade do todo.

Objetos de afro-americanos viram fases, a exemplo da fase Monjolo (JACOBUS, 1996), da Tradição Neo-brasileira do PRONAPA (1965-1970). Eurico Miller, em Santo Antônio da Patrulha (RS), no vale do Rio dos Sinos, investigava níveis estratigráficos como níveis cronológicos. Vale-se de características diagnósticas típicas para afirmar ocupações, tais como a cerâmica, a habitação, a iconografia, entre outras. As transformações culturais derivam de intervenção externas: contatos culturais, comércio e migrações. A informação contida no artefato dá segurança ao arqueólogo. Há fragilidade científica na orientação indutiva, examinando os materiais empíricos recolhidos, ordenando-os, classificando-os, eventualmente comparando-os, realizando generalizações subjetivas (TRIGGER, 1992: 195).

Ford (1938) valora os tipos dentro das culturas, correlaciona às diferenças temporais e especiais. A técnica de Mortimer Wheeler (1890-1976) é mais usada para o campo na escavação e no registro tridimensional. David Clarke (1968) cria o tratamento sistemático à tipologia arqueológica em todos os níveis (TRIGGER, 1992: 192-196). Na mesma época, vemos Mortimer Wheeler (1961: 27) criticar escavações que não deram importância às estratigrafias, buscando apenas estruturas arquitetônicas, o que se atmosfera na arqueologia histórica preocupada em comprovar um pensamento modelar em detrimento do universo subjetivo dos humanos envolvidos nestes sítios. Estas técnicas tornam-se fundamentais. "Es acientífico excavar sin plan ni problemas previos a cuya resolución puedan contribuir los dados, pero si se supiera lo que hay en el suelo antes de la excavación no habría razón para excavar" (WATSON; LEBLANC; \& REDMAN, 1974: 34). 
O Histórico-Culturalismo manteve-se até hoje sem renovação de técnicas nem implementação completa de seus pressupostos. Nas inúmeras conversas com Klaus Hilbert, entendi que a análise baseada em fósseis diretores, sistemas classificatórios e seriações geram uma redução interpretativa. Reduções parciais, evolucionismos, funcionalismos, estruturalismos e outros criaram a aura arqueológica desta época (final da segunda guerra até os anos 80, no Brasil). Hilbert diz que a descoberta do C14 rompe com a negação das antiguidades e dos períodos pré-cerâmicos. Isto justificava uma colocação de José Joaquim Justiniano Proenza Brochado (informação pessoal, em dezembro de 1992, Curso de Mestrado) de que Betty Meggers não estudava o lítico e preocupava-se muito mais com a cerâmica. Hilbert (2006) explica esta imagem por um "tripé" - objeto, tempo e espaço identificando fases e tradições, fórmulas fechadas.

A superioridade cultural, a assimilação, o abandono total da cultura, a vantagem de uma sobre as outras dava aos quilombos os aspectos de organização social, de produção de bens superados em sua origem africana pela superioridade da cultura européia. Quando trabalhei pela primeira vez com esta ideia, achava ser uma mera hipótese, mas não, isso é um pensamento que vigora ainda hoje no meio acadêmico. Escutei de uma antropóloga, que há anos trabalha com quilombos: "não devemos africanizar os quilombos"; logo depois indicou sua "origem italiana". Ela falava da aculturação dos quilombos. "Por mais que deseje, o cientista não pode eliminar inteiramente o seu imaginário para atuar em condições absolutas de objetividade e de neutralidade" (SILVA, 2012). A fala desta antropóloga é a atmosfera da cultura europeia como superior.

Repetidas vezes, vimos na história e seu reflexo na arqueologia o que nos escreve Joseph Hörmeyer (1986: 78), em 1850, preparando a propaganda para a entrada de alemães: "certo é que um escravo é castigado também aqui, mas assim como um pai castiga seu filho renitente”. Cristina Nery e Gilian Lopes (1988: 534-535) refutam a ideia de castigos brandos, pois nos escravos domésticos (1860-1880), cujas exigências eram menores, a taxa de aleijados e doentes era grande. A ideia de castigos sugere que existia esta necessidade e, portanto, explicita a imagem de inferioridade de época e atual, que se mantém entre pesquisadores e reflete no senso comum.

A escravidão, para alguns, impediu o desenvolvimento de eficientes formas produtivas, mantendo a sociedade em uma estrutura fechada, pois "sendo o escravo a base fundamental da estrutura, qualquer mudança estrutural, partindo da cúpula do sistema, previa o fim da condição de ser escravo como último ato, ou seja, o último recurso" (SANTOS, 1991: 72). Louis Conty (apud MAESTRI, 1984: 66) acredita que a charqueada gaúcha 
produziu menos que a uruguaia e a argentina, pois usava escravos em vez de assalariados. É evidente o eurocentrismo na história, refletindo-se na arqueologia.

Ocorre uma renovação na aura, com o marxismo na arqueologia, por ilustrar as lutas sociais e evidenciar a ação dos campesinos e trabalhadores. As ideias nacionalistas e evolucionistas agregam-se ao método de Mortimer Wheeler, dando base à arqueologia marxista na América Latina (TRIGGER, 1992: 170-172). A aura eurocêntrica está mantida.

É visível no universo antropológico de Darcy Ribeiro, no "O Processo Civilizatório" (1968), cujo prólogo é de Betty J. Meggers (RIBEIRO, 2001: 15), líder do PRONAPA. Meggers enfatizava que: "o mundo atravessa hoje um estado de sublevação. Guerras, rebeliões, golpes, guerrilhas, greves e outras manifestações de tensão comparecem diariamente nos jornais". Escreve que nos Estados Unidos estavam enfrentando "conflitos dos guetos negros", os quais "estão se tornando tão inevitáveis quanto os dias quentes de verão e agora ameaçam destruir porções apreciáveis de nossas principais cidades”. Indica já esta sublevação negra como um empecilho ao bom desenvolvimento. "Os conflitos raciais explodem por todos os lados. As enormes diferenças no acesso às vantagens econômicas e educativas não apenas criam problemas específicos, como difundem seus efeitos dilacerados através de toda a ordem social" (RIBEIRO, 2001: 15). Há uma dubiedade neste discurso, pois ao evocar o fim dos conflitos, explica-os pelo meio em que os afro-americanos vivem. Uma atmosfera típica das explicações marxistas na antropologia e na arqueologia brasileira.

Publiquei este livro com muito medo. (...) Meu medo devia ter aumentado quando um conhecido intelectual marxista, ledor de importante editora, deu um parecer arrasador sobre $O$ Processo Civilizatório. (...) Mas surgiram vozes de alento (...) Entre eles, a mais competente arqueóloga que conheço: Betty Meggers (Prefácio à quarta edição venezuelana, RIBEIRO, 2001: 23).

A imagem marxista invadiu a historiografia; há exemplo das obras de Fernando Henrique Cardoso (1962) e Jacob Gorender (1980), tendo como um dos principais seguidores no RS o historiador Mário Maestri. Basendo-se nesses, considerava o escravo como regulador social, pois quanto mais longe da condição de escravo um cidadão se encontrava, mais alto estaria na escala social. Era regulador de propriedade e a propriedade teria valor na cidadania de época; acredita que estes senhores não podiam imaginar sua vida sem seus escravos, sem seu trabalho. Identifica, segundo suas pesquisas, inúmeros casos de escravos valerem mais que uma propriedade, funcionando também como moeda internacional-comercial (MAESTRI, 1984: 25) e como indexador da economia interna (SANTOS, 1991: 71-72). 
Gilbert Durand (2004: 15) diz que "não nos habituaram a ler (...) através de um contexto de remitologização". A atmosfera do "herdeiro glorioso das Luzes" é que guia este momento da ciência, tanto no positivismo como no materialismo

Pelo menos não são nossas teorias eruditas das ciências sociais do século XIX que procuraram desmitificar nossa quietude progressista! Entretanto... Entretanto Saint Simon, Auguste Comte, principalmente, querem fundar, e fundam (no Rio de Janeiro, esta instituição ainda existe...), uma religião nova com sua liturgia, seu temporal, e mesmo seu santoral! E, no entanto... Sabe-se lá por que Karl Marx deixou crescer uma barba tão bonita, a mais bela barba da história moderna? Simplesmente pela sua admiração por um busto helenístico de Júpiter (o qual ele sempre guardou, em Londres, a forma na ante-sala do seu escritório), ele mesmo se sonhando como sendo o Olimpiano fundador dos novos tempos. Teogonia é o primeiro modelo de um certo progressismo: após a idade dos Titãs, após o reino de Cronos, de repente advém a idade das Luzes olimpianas, a idade da ordem jupiteriana... É exatamente com este Zeus do Olimpo que Karl Marx quis conscientemente, muito conscientemente, parecer... Então, clima estranho este do século XIX, aonde o progressismo vai em direção do avanço tecnológico triunfante até nossa própria época, mas onde os construtores de ideologias totalmente míticas (no sentido bem pejorativo como entendiam os positivismos, quer dizer inverificáveis, utópicas, fantasmáticas...) assombram a ascetização racionalista. (DURAND, 2004: 15)

A mítica higienizante do materialismo onde a mão-de-obra afro-americana ocupou todas as instâncias da produção no RS, africanos/escravos como uma abstração. Homogeinização de diferentes grupos linguísticos, que divididos em dialetos e tribos não formam uma unidade, impedidos de permanecer reunidos (SANTOS, 1991: 75). Homogeinização como classe ou cultura, uma mítica positivista/materialista. Os escravos do Brasil meridional foram utilizados no campo, mas em concentração nas charqueadas. Os escravos eram então estenuados por uma jornada de trabalho de 16 horas diárias, apanhando e sendo muitas vezes embebedados para continuar seu trabalho, parando pelo esgotamento ou pela enfermidade (MAESTRI, 1984: 46). A carne salgada barateava o antigo transporte do gado vivo, a produção intensa, competitiva com as saladeiras argentinas e uruguaias que, depois de 1825, passaram a usar assalariados (CORSETTI, 1985: 91).

Os sítios de afro-americanos nesta mítica mantêm o "modo de produção" ou um "modelo de subsistência" no "modo de produção capitalista" implementado, relegando ao universo materialista a mítica dos quilombos. A atmosfera em que há a modelação marxista, entendendo o capital industrial como motor da mudança, cria um apelo às relações de poder mecanicamente. O viajante Nicolau Dreys (apud MAESTRI, 1979: 42) considerou a charqueada um estabelecimento penitenciário. No espaço urbano, esta "classe" teria melhorias da vida; e no campo e charqueadas, os escravos estavam mais angustiados (MAESTRI, 1990: 697-698; MAESTRI, 1984: 63). 
Afirma-se que o escravo na cidade se protege entre os seus, os escravos de ganho conquistam a liberdade pela compra de alforrias (MAESTRI, 1990: 699-701-703-705; ISCM, 1994: 51). A circulação livre, jogos, liberdades, eram punidos severamente (MAESTRI, 1990: 699-700) subverte a imagem de classes diferentes entre os escravos ou mesmo do escravo como classe (MOREIRA, 1995: 54). Esta é uma mítica atual nos estudos arqueológicos sobre o negro (CARLE, 2005).

As alforrias geravam inúmeras contradições. Roberto dos Santos, ao catalogar uma série de inventários, encontrou um fato curioso em que um escravo possuía escravo (SANTOS, 1991: 112). A pureza ingênua marxista na arqueologia embasada na estratigrafia (TRIGGER, 1992: 186-195) é contra esta imagem. Esta arqueologia evidencia os sítios relacionados a assentamentos de afro-americanos, fruto de discussões internas da ciência no sentido dos limites de seu objeto de estudo em conflito com a história e com a antropologia, principalmente, mas que suscitou na definição da própria ciência como uma disciplina em construção (KERN, 2002: 118). A arqueologia é um estudo da cultura material no seu relacionamento direto com o comportamento humano (KERN, 1996: 7). Ela se ocupa também do ambiente em que gênio (ou gênero humano) se desenvolveu e no qual o homem ainda vive (RAHTZ, 1989: 9).

Este mundo pré-determinado por modelos é o mundo da ciência moderna que se arvora a dar sentido à vida pelos modelos (SILVA, 2012). Wheeler (1961: 78) sugeriu que se realizassem escavações em área, com sondagens preliminares para a verificação de estratigrafia. A escavação em área seria possibilitada, para o autor, sem a perda do referencial da estratigrafia, realizando um quadriculamento que manteria "bermas" laterais (paredes em quadrículas) para a visualização estratigráfica e bem como a circulação de operários, com carrinhos e baldes de terra (1961: 80). O método permite uma distinção de diacronia e sincronia, sendo possível detectar os níveis de alteração dos comportamentos dos sítios e, por conseguinte, dos indivíduos que ali se estabeleceram durante o processo de formação dos mesmos. Soluciona problemas nos sítios tais como a composição por uma série de estruturas arqueológicas e arquitetônicas diferenciais à malha arqueológica; a escavação é feita conforme as questões levantadas previamente, pois escavar não é fazer arqueologia, a arqueologia é interpretação. Uma arqueologia hermenêutica. Esta atmosfera atinge os arqueólogos brasileiros.

Salete Neme (1988: 31-44) faz uma espécie de arqueologia antropológica com base marxista. O contato visto como "fricção interétnica" ocasionada por duas formas de viver em atração, onde culturas distintas não se exterminaram, mas permitiram uma transformação 
cultural. Nos assentamentos de afro-americanos teríamos no mínimo duas culturas em contato. Uma que liga profundamente o indivíduo à natureza, de maneira mais fixa - "sociedades primitivas" -, e outra de característica mercantilista ligada a um sistema colonial.

Funari (1996) inicia uma nova atmosfera mais ligada à própria ideia dos quilombolas sobre suas organizações. As estruturas defendiam a população e sua economia. A ideia econômica ocidental é base permanente desta atmosfera da historiografia e não usufruímos de muitos textos divergentes na arqueologia.

O universo da praticidade econômica e política na formação dos quilombos invade a cena de forma mesmo a criar uma atmosfera "primitiva" na constituição dos quilombos, mas não numa análise simbólica de seus criadores. As armas mais comuns eram arcos, flechas, lanças e armas de fogo tomadas das expedições punitivas ou compradas (MOURA, 1987: 1855). É a atmosfera de uma utopia ocidental. A multiplicação dos quilombos constrói um espaço social de autonomia política consciente (SANTOS, 1991: 79). As atividades contra os quilombos eram problemas políticos (MAESTRI, 1979: 72 - 86). O discurso é reproduzido nos textos arqueológicos (ALLEN, 2006). O trabalho arqueológico é usado para referendar o discurso (CARVALHO e PORTO, 2007 [2012]).

A Nova Arqueologia desloca a atenção do artefato para os sistemas sócio-culturais que afirmam tê-los produzido e utilizado (processo cultural). Realiza por indagações sobre articulações do homem com o meio. Cientificidade é almejada, os métodos hipotéticodedutivos, a experimentação e a formulação de modelos e leis científicas (MENEZES, 1983), ou seja, a mítica agora transforma vida em mecânica abstrata.

Já na atmosfera dos arqueólogos antropológicos (HODDER, 1988: 203) há uma visualização das sociedades conhecidas hoje, com encargos aparentemente antigos, que foram mantidos por uma (con)tradição interna a própria teoria. Os arqueólogos buscam no material seus usos e funções, pensando no todo cultural, inferindo a vontade ou não do artesão, expressa nos traços reconhecidos pelo observador, o qual deveria reconhecer a totalidade dos componentes para identificar uma ação ou momento do acontecimento histórico.

A Etnoarqueologia, baseada na etnohistória e etnografia, toma assento mítico na ciência. "A utilização de dados etnográficos na pesquisa arqueológica não é nenhuma novidade, e sempre houve quem tenha recomendado tal procedimento" (MILLER, 1981: 82293). Tom Miller (1981/82) refere que etnoarqueologia se faz com Analogia, em dois níveis: o primeiro, a "analogia etnográfica", que seria formalista, e o segundo de uma "abordagem histórica direta". A abordagem histórica direta examinaria o "comportamento de grupos contemporâneos em termos da probabilidade de se poder entender o mesmo comportamento 
diretamente até os períodos pré-históricos" (MILLER, 1981/82: 294). O projeto de pesquisa arqueológica sobre a República de Palmares, Pedro A. Funari (Unicamp), Charles Orser Jr. (Illinois State University) e Michael Rowlands (University College London), estudam a cultura material do afro-americano, pela arqueologia entendendo a existência de uma cultura africana em liberdade, nos quilombos (FUNARI, 1996). Este trabalho, por relacionar os conhecimentos dos afro-americanos diretamente envolvidos, realizou uma amplificação na atmosfera arqueológica de forma inimaginável até então. Há uma aproximação às generalizações empíricas testáveis, conduzindo à teoria. Remontável da generalização à teoria, da teoria à implicação testável, e desta ao teste de proposição. Nos assentamentos negros, considero esta abordagem válida, no sentido de que este grupo foi documentado no passado. Tal modelo foi viável mesmo com uma documentação etnohistórica e etnográfica que estava defasada.

O uso da etnografia pela arqueologia gera alguns problemas. A antropologia tende hoje a se colocar em outro nível de relação com seu objeto de estudo. "A única etnografia da qual o antropólogo social tem um conhecimento íntimo é a que deriva de sua própria experiência de vida" (BRANDÃO, 1982: 13). O arqueólogo, que se vale das descrições antropológicas e de viajantes, interpreta com cautela estas fontes, no sentido de perceber onde está uma descrição com menor subjetividade e onde a subjetividade do autor impera (é outra atmosfera a ser estudada).

A arqueologia "pós-processual" (TRIGGER, 1992: 351) realiza uma leitura da cultura material através da dicotomia entre materialismo e ideologia, pensando variabilidade na análise do poder; isto se faz por intermédio da cultura material que margeia os grupos, servindo também para o controle da análise. Busca também verificar a dicotomia entre processo e estrutura, onde a permanência pode ser observável através de dados reais, mas não objetivos. Caracteriza-se por um antagonismo entre subjetividade e objetividade do observador (arqueólogo) na interpretação de dados. Esta não estaria confinada, então, a um relativismo.

Cabe dizer que no estudo sobre o imaginário "essencialmente motriz e sedimentação estratigráfica, como num terreno com vestígios arqueológicos separados por camadas temporais" há uma consolidação do ente humano simbólico. "O homem é homem por construir imaginários que o impulsionam no processo infindável de humanização. A superstição é um exemplo de racionalização imaginária" (SILVA, 2008, [2012]: 05). 


\section{Considerações finais}

O imaginário social estrutura-se principalmente por contágio: aceitação do modelo do outro (lógica tribal), disseminação (igualdade na diferença) e imitação (distinção do todo por difusão de uma parte). No imaginário há sempre desvio. No desvio há potencialidade de canonização. O imaginário explica o "eu" (parte) no "outro" (todo). Mostra como se permanece individual no grupo e grupal na cultura. (SILVA, 2012).

As aspirações à universalidade, "não são mensuráveis, embora perceptíveis", a mítica agora é o "que cada cultura engendra para si mesma". A cultura é "um dado objetivo". A atmosfera, o imaginário, são formas abstratas de um concreto vivido. "A objetividade da cultura diluiu-se nas águas pesadas da atmosfera imaginal". "O espiritual incide" sobre a cultura material. "O imaginário toma forma material e deforma o espiritual. Dá-lhe carne e sangue". (SILVA, 2008 [2012]: 05).

Atmosfera criada pela própria ciência que é reservatório, um motor que agrega imagens, segue um trajeto criador da atmosfera que se representa nela como um todo. Podemos verificar que de uma atmosfera básica eurocêntrica e sem valorizar outras manifestações, avançou-se para um modelamento da arqueologia brasileira, uma arqueologia científica. Neste processo, o marxismo foi crucial, mas não rompeu com a mítica do progresso. A mistura destas diversas atmosferas hoje criou uma arqueologia de quilombos esquizóide, mas uma nova atmosfera está se constituindo nos estudos de sítios de afro-americanos.

Uma série de mitos constitui este Trajeto (DURAND, 1997); cria-se um mundo de modelos pré-determinados e segue-se ideologemas de superioridade cultural. A base principal destes mitos e ideologemas é o evolucionismo. A ciência da cultura material é entendida pelos seus usos e funções na interlocução com o meio. O materialismo histórico (e com isso uma aura econômica) toma a frente das ideias e chegamos a uma arqueologia modelada, numa atmosfera de cientificidade eurocêntrica. Os movimentos sociais (assim como a própria arqueologia social) bebem dos mesmos ideais marxistas e invadem o campo da ciência. As lutas políticas tomam assento na atmosfera que se poderia pensar em conflito entre pesquisadores e comunidade, mas que em realidade falam a mesma língua. Espera-se que futuramente uma nova aura se instale; a que reconhece a existência de uma cultura africana nos sítios de negros no Brasil. Resposta é compreender a atmosfera dos seus sujeitos - os negros.

No texto que produzi (CARLE, 2005), trouxe de Rederam (1973), Unidade Sociológica desenvolvida por Funari (1988) associada à Arqueologia Histórica (ORSER, 
1992), para o meu estudo dos afro-americanos no Delta do Jacuí e Rio dos Sinos; segui ideias de Ian Hodder (1988: 179-202), estudando o conteúdo étnico. Apresentei minha Tese como simbólico-religiosa, mas estava no campo do imaginário e não sabia.

Klaus Hilbert poderia então dizer que se não está no registro arqueológico, não está na arqueologia, pois só trabalhamos com o que podemos ver e interpretar. O que não pode ser lido hoje não é passível de ser argumentado. E se não podemos argumentar hoje o que não vemos, não podemos condenar os arqueólogos do passado pela impossibilidade de terem visto.

O aprendizado anterior, com os professores citados, marca o meu trabalho. Hoje, consolidada a "colaboração" numa relação entre as ciências da Antropologia, Arqueologia, História (SCHWARTCZ, 2000: 11), conservação e restauro e museologia. O trabalho que desenvolvemos no LAMINA (Laboratório Multidisciplinar de Investigação Arqueológica), em conjunto com colegas da museologia (Diego Ribeiro e Pedro Sanches), da Conservação e Restauro (Jaime Mujica), da Arqueologia (Lúcio Ferreira e Aluísio Gomes Alves), da Antropologia (Rogério Rosa), entre outros, nos possibilita isso nos estudos de sítios de negros.

Portanto, nossa civilização ocidental tinha sido muito desmitificante e iconoclasta. O mito era relegado e tolerado como o «um por cento» do pensamento pragmático. Bom, sob nossos olhos, em uma aceleração constante, esta visão do mundo, esta concepção do ser, do real (Wesenschau), está desaparecendo. Não somente mitos eclipsados recobrem os mitos de ontem e fundam o epistema de hoje, mas ainda os sábios na ponta dos saberes da natureza ou do homem tomam consciência da relatividade constitutiva das verdades científicas, e da realidade perene do mito. $\mathrm{O}$ mito não é mais um fantasma gratuito que subordinamos ao perceptivo e ao racional. É uma res real, que podemos manipular para o melhor como para o pior. (DURAND, 2004: 20)

\section{Referências bibliográficas}

ALLEN, Scott J. “As vozes do passado e do presente: arqueologia, política cultural e público na Serra da Barriga”. CLIO - Série Arqueologia. V. 20 (1), (pp. 81-101), 2006.

BRANDÃO, Carlos Rodrigues. Diário de campo - antropologia como alegoria. São Paulo: Brasiliense, 1982.

CARDOSO, Fernando Henrique. Capitalismo e escravidão no Brasil Meridional. São Paulo: Difusão Europeia do Livro, 1962.

CARLE, Cláudio B. A organização espacial dos assentamentos de ocupação tradicional de africanos e descendentes no Rio Grande do Sul, nos séculos XVIII e XIX. Tese de doutorado, PUCRS, Porto Alegre, 2005. 
CARVALHO, Patricia M. de; PORTO, Vagner C. (Oror). "Arqueologia de Quilombo" Anais do $10^{\circ}$ Congresso de Iniciação Científica, $4^{a}$ mostra de Pós-Graduação e $1^{a}$ Mostra do Ensino Médio. São Paulo: UNISA - Universidade de Santo Amaro. 6 a 8 de Nov. 2007, disponível em http://unisa.br/pesquisa/arquivos/livro_10 congresso.pdf\#page=589 acesso em Dez. 2012.

CHILDE, Gordon. Introdução à arqueologia. Lisboa: Publ. Europa-América Ltda. (Coleção Saber), 1961.

CORSETTI, Berenice. "Estudos da Charqueada Escravista do Rio Grande do Sul" in: História: ensino e pesquisa, ano 1, $\mathrm{n}^{\circ} 1$, Porto Alegre: APHRGS, Sulina, 1985.

DURAND, Gilbert. "O retorno do mito: introdução à mitodologia. Mitos e sociedades". Revista FAMECOS (quadrimestral) Porto Alegre: PUCRS, nº 23. abril (pp. 7-21), 2004.

DURAND, Gilbert. As Estruturas Antropológicas do Imaginário. São Paulo: Martins Fontes, 1997.

FAUSTINO, Gitibá G. "O negro gaúcho e suas origens" In: TRIUMPHO, Vera (Org.) Rio Grande do Sul - Aspectos da Negritude Porto Alegre: Martins Livreiro, (97-103), 1991.

FUNARI, Pedro P. A. Arqueologia. São Paulo: Editora Ática, 1988

FUNARI, Pedro P. A.; CARVALHO, Aline; Palmares, Ontem e Hoje. Rio de Janeiro: Jorge Zahar Ed., 2005.

FUNARI, Pedro P.A. "A República de Palmares" e a Arqueologia da Serra da Barriga, Revista USP, 28, 6-13, 1996.

GOMES, José; MACHADO, Helena, VENTMIGLIA, Marise. Arquipélago: As Ilhas de Porto Alegre, Memórias dos Bairros, Porto Alegre: Unidade Editorial, PMPA, (prelo), 1995.

GOMES, Nilma Lino. Apresentação In: SCHWARTZ, Lilia Moritz e GOMES, Nilma Lino Antropologia Histórica. Debate em região de fronteira. Belo Horizonte: Ed. Autêntica, 2000.

GORENDER, Jacob. O escravismo colonial. 3. ed., Série Ensaios - 29, São Paulo: Ática, 1980 .

HILBERT, Klaus. "Qual o compromisso social do arqueólogo brasileiro?" Revista de Arqueologia, Sociedade de Arqueologia Brasileira, 19 (pp. 89-101), 2006.

HODDER, Ian. Interpretación en arqueologia. Barcelona: Ed Crítica, 1988.

HORMEYER, Joseph. O Rio Grande do Sul de 1850 - Descrição do Rio Grande do Sul no Brasil Meridional. Porto Alegre: D.C. Luzzato, EDUNI-SUL, 1986.

ISCM - SANTA CASA DE MISERICÓRDIA. Negros Cativos e Livres na Irmandade Santa casa de Misericórdia. Porto Alegre: ISCM, CEDOP, 1994. 
JACOBUS, André Luiz. Resgate arqueológico e histórico do registro de Viamão: Guarda Velha, Santo Antônio da Patrulha - RS. (Dissertação de mestrado) Porto Alegre: PUCRS, 1996.

KERN, Arno Alvarez. "O futuro do passado: os arqueólogos do novo milênio" Trabalhos de antropologia e etnologia. Vol. XLII (1-2), (pp. 115-136), Porto: Sociedade Portuguesa de Antropologia e Etnologia, 2002.

KERN, Arno Alvarez. "O papel das teorias como instrumental heurístico para reconstituição do passado”. Histórica vol. 1, (pp. 7-22), Porto Alegre: APGH-PUCRS, 1996.

LAET, Sigfried J. de. "La arqueologia y sus problemas". Colección labor, Sección VI, Ciencias Historicas, Barcelona: Biblioteca de Iniciación Cultural, Ed Labor, 1960.

LIMA, Tânia A. "Arqueologia Histórica: algumas considerações teóricas" In: I Seminários de Arqueologia Histórica. Rio de Janeiro: SPHAN/FNPM, outubro, (pp. 87-99), 1985.

MAESTRI, Mário J. “O Escravo Africano no Rio Grande do Sul” In: DACANAL, José H. e GONZAGA, Sergius (org.) RS: Economia e Política. Porto Alegre: Mercado Aberto, (29 54), 1979.

MAESTRI, Mario J. Depoimentos de Escravos Brasileiros. São Paulo: Ícone Edições, 1988.

MAESTRI, Mario J. "O ganhador, o alforriado, o bacalhau”. Veritas, vol. 35, $\mathrm{n}^{\circ}$ 140, Porto Alegre: PUCRS, (695 - 705), 1990.

MAESTRI, Mario J. "O escravo gaúcho. Resistência e Trabalho" Coleção Tudo é História vol. 93, São Paulo: Brasiliense, 1984.

MAESTRI, Mario J. Quilombos e Quilombolas em Terras Gaúchas. Porto Alegre: ESTSLB, Univers. de Caxias, 1979.

MAFFESOLI, Michel. "Le sens commun". In: Société. Revue des Sciences Humaines et Socieles - Paris: No 46:387-397, 1994.

MENESES, Ulpiano Bezerra de. A Cultura Material no estudo das Sociedades Antigas. Depto de História, FFLCH - USP, São Paulo: s/d.

MENEZES, Ulpiano Bezerra de. A "New Archaeology: a arqueologia como ciência social". Diálogos sobre arqueologia. Terceira série, ano 1, $\mathrm{n}^{\circ} 1,1983$.

MILLER, Tom O. "Etnoarqueologia: Implicações para o Brasil". Arquivos do Museu de História Natural. Vol VI/VII, Belo Horizonte: Museu de História Natural, 1981/82.

MOREIRA, Paulo R. S. "E a rua não é do Rei - Morcegos e Populares no início do policiamento urbano em Porto Alegre - Século XIX". In.: HAGEN, Acácia \& MOREIRA, Paulo (org.) Sobre a Rua e Outros Lugares - Reinventado Porto Alegre, , Porto Alegre: AHRGS - CEF/RS (51 - 96), 1995.

MOTT, Luiz. "Acundá: Raízes Setecentistas do Sincretismo Religioso Afro-brasileiro". Revista do Museu Paulista, Nova Série, Vol. XXXI, USP, São Paulo: (124 - 147) 1986. 
MOURA, Clóvis. "Quilombos e Rebelião Negra, 7ª ed" Tudo é História - Vol. 12, São Paulo: Brasiliense, 1987.

NEME, Salete. "O contacto interétnico entre europeus e sociedades tribais no Rio de Janeiro". Revista de arqueologia. Vol 5, n¹, Rio de Janeiro: SAB - CNPq, 1988.

NERI, Cristina D. e LOPES, Gilian. "Relação Senhor - Escravo". Veritas, Vol. 33, n 132, Porto Alegre: PUCRS, (533 - 535), 1988.

O MENSAGEIRO, Jornal Farroupilha, Porto Alegre, 1835 - 1836.

ORSER JR., Charles E. Introdução a arqueologia histórica. Coleção Mínima, Ciências Sociais, Belo Horizonte: Oficina de Livros, 1992.

PROUS, André. Arqueologia brasileira. Brasília: Ed. UNB, 1991.

RAHTZ, Philip. Convite a arqueologia. Série Diversos, Rio de Janeiro: Ed. Imago, 1989.

REDMAN, Charles L. "Multistage Fieldword and Analitical Techniques". American Antiquity. Vol 38, no. 1, 1973.

RIBEIRO, Darcy. O processo civilizatório: Estudos de antropologia da civilização (2a reimpressão) São Paulo: Companhia das letras, 2001.

SANTOS, Júlio Q. dos. "Reverso na Trajetória Historiográfica do Negro Sul-Rio-Grandense: A Face Oculta da Escravidão". In: TRIUMPHO, Vera (Org.) Rio Grande do Sul - Aspectos da Negritude Porto Alegre: Martins Livreiro, (131 - 142), 1991.

SANTOS, Roberto dos. "O Negro no Rio Grande do Sul : uma Realidade além do Mito". In: TRIUMPHO, Vera (Org.) Rio Grande do Sul - Aspectos da Negritude. Porto Alegre: Martins Livreiro, (107 - 114), 1991.

SANTOS, Roberto dos. "Três pontos de Reflexão sobre o Negro no Brasil". In: TRIUMPHO, Vera (Org.), Rio Grande do Sul - Aspectos da Negritude. Porto Alegre: Martins Livreiro, (71 - 83), 1991.

SCHMITZ, Pedro Ignácio. "Avaliação e perspectiva". n 47, Arqueologia, Ciências Humanas e Sociais - SEPLAN- CNPq, 1982.

SCHWARTZ, Lilia Moritz. "Introdução. História e Antropologia: embate em região de fronteira”. In: SCHWARTZ, Lilia Moritz e GOMES, Nilma Lino Antropologia e história. Debate em região de fronteira. Belo Horizonte: Ed. Autêntica, 2000.

SILVA, Juremir Machado da. Tecnologias do imaginário: esboços para um conceito, Disponível em http://leandromarshall.files.wordpress.com/2008/01/tecnologias-doimaginc3a1rio1.pdf acesso em agosto de 2012.

TRIGGER, Bruce G. História do pensamento arqueológico. Barcelona: Editorial Cítica, 1992. 
WATSON, Patty Jo; LE BLANC, Steven A; REDMAN, Charles L. El metodo cientifico en arqueologia. Madrid: Editora Alianza, 1974.

WHEELER, Mortimer. Arqueologia de campo. México: Fondo de Cultura Econômica, 1961. 